\title{
AC 2012-4796: A QUARTER-CENTURY OF TEACHING SPACECRAFT MISSION DESIGN
}

\section{Dr. Wallace T. Fowler P.E., University of Texas, Austin}

Wallace Fowler has served on the faculty of the Department of Aerospace Engineering and Engineering Mechanics at the University of Texas, Austin, since 1965. He is a Fellow of both the American Society for Engineering Education (ASEE) and the American Institute of Aeronautics and Astronautics. He served as National President of the ASEE in 2000-01. He currently directs the NASA Texas Space Grant Consortium. He was the recipient of the 1985 AIAA/ASEE John Leland Atwood Award and the 1994 ASEE Fred Merryfield Design Education Award. 


\section{A Quarter-Century of Teaching Spacecraft-Mission Design}

After more than twenty five years of teaching a capstone spacecraft-mission design course in an aerospace engineering curriculum, the instructor looks back on the evolution of the course and changes in student capabilities. The evolution in course structure, types of projects, project depth, and instructor understanding of the design process are discussed. The effect of the tremendous increase in information available to students through the Internet is discussed.

\section{Instructor Background}

The author became a member of the faculty at The University of Texas at Austin in September 1965. From 1965 through 1981, he taught a variety of aerospace engineering and engineering mechanics analysis courses. His doctoral work was in the area of spaceflight trajectory analysis. However, between 1965 and 1981, he taught many different courses, including statics, dynamics, aircraft flight mechanics, flight test engineering, space flight mechanics (basic orbital mechanics), and attitude dynamics. During this time period, he never even thought about teaching design.

In 1981, the author was invited to spend the 1981-82 academic year as a visiting faculty member in the Department of Astronautics at the United States Air Force Academy (USAFA). During that year, he taught space flight mechanics courses and sections of a tightly structured design course. This course, then designated as Engineering 430, was designed by USAF Col. John P. Wittry. The course was tightly structured, designed for instructors beginning teaching at the Academy after various non-academic Air Force assignments. The design topics ranged from aircraft and space related design topics to the design of devices to help patients at the Rocky Mountain Rehabilitation Center.

The course materials had been designed for USAF officers coming from a variety of duty assignments, ranging from missile silo duty to fighter and transport pilots. Almost none of the incoming instructors had PhDs and few of them had teaching experience. Thus, the course materials were very detailed and complete. Col. Wittry had long experience in the USAF acquisition process and long teaching experience. The students were issued an RFP with a cutdown version of the USAF "boilerplate documents" as part of the course. The students had to research the design topic, write a proposal, negotiate a contract with the instructor, create a design, conduct mid-semester and end-of-semester design reviews, and prepare mid-semester and end-of-semester design documents.

This was an ideal academic environment in which to learn about teaching design. The author taught one section of the course in both the fall and spring semesters and took over a second section in the spring when an officer-instructor left for another duty station. The experience was career changing for the author.

After the year at the USAFA, the author returned to his home institution where he introduced a spacecraft-mission design course in spring 1984. The early course was basically a clone of the USAFA design course with space-related topics. With USAFA approval, the instructor even 
used the USAF "boilerplate documents" Request for Proposal (RFP). Beginning in fall 1984, the aerospace engineering curriculum was revised to allow the students to choose one of two seven semester-credit-hour technical areas (atmospheric flight or space flight) as the culmination of their degree program. All students were require to take an aircraft flight dynamics course and a basic space flight dynamics (orbital mechanics) course. The courses in the space flight technical area were a three semester-credit-hour attitude dynamics course, a one semester-credit-hour trajectory/attitude modeling laboratory, and the three semester-credit-hour spacecraft-mission design course.

The timing of the introduction of the spacecraft-mission design course was fortunate. In 1985, NASA, working through the Universities Space Research Association (USRA), created a pilot program for what was later known as the NASA/USRA Advanced Design Program (ADP). Six schools were asked to be part of the pilot program, and UT Austin was one of the six.

The ADP expanded and by the time the program ended in 1995, there were teams from 40 universities across the United States in the program. The ADP provided teams new to the program $\$ 25 \mathrm{~K}$ per year to pay for a design teaching assistant and student travel to a design conference at the end of the academic year at which all student team designs were presented. Teams in the program for longer than three years received only $\$ 17 \mathrm{~K}$ per year for team travel costs as the institution was expected to pick up the cost for the teaching assistant.

During the years from 1985 through 1995, the author alternated semesters teaching the course with Dr. George Botbyl, an adjunct faculty member from the UT Center for Space Research. Dr. Botbyl and the author worked with the student design teams every semester, effectively team teaching the course. In fall 2000, when the author was president of ASEE, the course was taught by Dr. P.A.M. Abusali, another adjunct faculty member from the Center for Space Research.

Participation by student teams in the design conference produced an unexpected result. The design faculty involved noted that each year, the quality of the previous year's best presentations was the quality norm for the current year's presentations. This was unexpected because new students were on the teams each year. The change had to be due to higher expectations communicated through the design faculty and teaching assistants. Details about the ADP can be found in a 1988 AIAA paper by Johnson and Rumbaugh [1].

UT Austin student aerospace engineering teams participated in the ADP for all ten years (fall 1985 through spring 1995) of the program's existence. This participation resulted in a maturing of the course and expectations which has continued into the present. The overall effect of the program on design at UT Austin is detailed in a paper by Fowler, et.al. [2].

During the early 1990's the author also offered a graduate level spacecraft - mission design course. The graduate students produced a document that characterized spacecraft subsystems for use by the undergraduate design students. This document was used by regularly undergraduate teams until internet access became common, and the information was readily available on the web. 
In 2006, the NASA Exploration Systems Mission Directorate (ESMD), sent a practicing systems engineer, Lisa Guerra, to UT Austin to assess the possibility of introducing Systems Engineering(SE) into both graduate and undergraduate engineering curricula. The NASA engineer developed learning modules for a three semester-credit-hour introduction to systems engineering course. A significant number of the modules were included in the fall 2007 capstone spacecraft-mission design course. The results were less than optimal. The addition of the SE modules to the design requirements overloaded the students. The resulting designs were better structured from a SE point of view, but most were technically less mature than before. The decision was made to offer the three semester-credit-hour SE course as an elective in spring 2008 and to urge students to take the course.

At the same time that the SE course was being developed, the aerospace undergraduate curriculum was being revised. The revision consisted of rearranging courses to increase the two technical areas (atmospheric flight and space flight) from seven semester-credit-hours to thirteen semester-credit-hours. The new curriculum went into effect in fall 2008, and the space flight technical area now included an advanced orbital mechanics course ( $3 \mathrm{hrs})$, an attitude dynamics course ( $3 \mathrm{hrs})$, the systems engineering course ( $3 \mathrm{hrs})$, a spacecraft subsystems modeling laboratory ( $1 \mathrm{hr}$ ), and the spacecraft-mission design course ( $3 \mathrm{hrs})$. In the 2008 curriculum revision, the SE course and the subsystems modeling laboratory were made prerequisites for the capstone spacecraft-mission design course.

In another development in 2007, students from department who had gone to work at JPL after graduation began to suggest design topics for student design teams. This has now evolved into a system in which JPL provides design topics and mentors for student teams. The mentors work with the teams throughout the semester and a subset of the JPL mentors come to campus to hear the final oral design presentations at the end of the semester.

\section{Course Features}

There are a number of course features that have evolved over the last 27 years. These features and the reasons for them are discussed below. We ask students who are taking two to four other courses, to work in small teams over a semester and try to simulate what a team of full time engineers to do in developing a proposal for a major project. Sometimes the full time engineers take months to years to develop ideas. Many of the course features are designed to streamline the process of obtaining the background information, choosing formats for various deliverables, etc. Other course features are designed to assure that designs are on schedule, that all students contribute to the design, and that the work of individual students is recognized appropriately.

Course Prerequisites - Students taking the course have taken both the three semester-credithour introduction to systems engineering (SE) course and the one semester-credit-hour spacecraft subsystems modeling laboratory. Details of these courses and how they affect the design course are given in Reference [3]. The course modules for the SE course can be found on the Internet at the National Space Grant Foundation website, Reference [4].

Course Objectives - There are many ways to add more detail to the course objectives, but at the top level, the objectives are: 
Students successfully completing this course will have:

- Worked in a situation in which the team members take responsibility for defining what is to be done and which problems to solve, as well as when a solution is acceptable.

- Worked effectively as a member of a team developing a preliminary design of a spacecraft, space mission, and/or other space-related system.

- Effectively used team processes

$\circ$ Participated in the writing and refinement of requirements and rationales for those requirements

- Participated in developing design concepts, concepts of operations, and making design decisions

- Researched and analyzed performance of the design candidate subsystems and presented the results to the team for possible inclusion in the final design

- Given two or more technical oral presentations about aspects of their team's design and received feedback on their presentations.

- Developed effective, concise, and well written sections for the team's mid-term and final reports

○ Provided other design documentation as needed for the team's presentations and reports

- Learned that as graduating engineers, they are capable of creating a design to meet a need without an instructor telling them how to do it.

Detailed Syllabus - The spacecraft-mission course syllabus has evolved and is stable. To conserve space, several institution-specific items have been deleted (notices about religious holy days, students with disabilities, etc.). The syllabus for fall 2011 is provided in Appendix A. The syllabus is very complete so that the students know from the start that a lot of work is expected and there is a tight schedule for completion of that work.

Published Course Timeline / Deliverables List - The number and types of deliverables has evolved to a point where every deliverable is assigned a specific date before the semester begins and the students are given the schedule on the first day of class. The only exception to this is the date of the final oral presentations. The final presentations are scheduled so the team mentors from JPL can attend, and the mentors usually do not know their availability three to four months in advance. The students are made aware of this on the first day of class. A sample course timeline and list of deliverables list are given in Appendix B.

Example Documents - Sample documents from projects done in earlier semesters are made available to students. This includes Technical and Management Proposals, Concepts of Operations (ConOps), mid-semester presentations, mid-semester reports, requirements documentation, final presentations, and final reports. In addition, students are provided with generic recommended outlines for the mid-term and final reports.

With the proliferation of information on the Internet, students can find many types of information about almost any topic. Legacy folders (old homework, projects, lab reports, tests, etc.) exist for most of the courses taught today and many faculty members seem unaware of this 
fact. The sample documents provided on the Blackboard classroom management system are from recent high quality projects involving missions different from those under consideration by current teams. However, if a team wants to see the reports from an earlier team that worked on a similar mission, they are allowed to do so with the proviso that they are building on the shoulders of that team and their design must be different and hopefully better than that of the earlier team.

Access to Systems Engineering (SE) PowerPoint Presentations - The students have easy access over the Internet to the PowerPoint slides from the prerequisite SE course. However, when discussing design topics covered in the SE course (ConOps, requirements, trade studies, etc.), the SE slides for that topic are placed on the design course Blackboard website so that the students have easy access to the information.

Blackboard Postings - UT Austin has adopted the Blackboard electronic course management system. All course documents including the syllabus, course timeline, sample proposals, sample presentations and reports, suggested outlines for presentations and reports, special references, etc., are placed on the website. This is an efficient way to communicate with teams.

Spacecraft Subsystems Information - In the late 1980s, the instructor also taught a graduate level space mission planning course. As part of this course, he had the graduate students in the class create a document that characterized the various common subsystems on a spacecraft. The goal was to identify the parameters that determine the performance, volume, power requirements, and mass of various spacecraft subsystems and to make this information available to other students (i.e., undergraduate design students). This graduate student produced document was used until the fall 2008 curriculum revision in which the one semester-credit-hour spacecraft subsystems modeling laboratory became a prerequisite for the design course. The information in the new laboratory is much better organized and up to date than the earlier document.

Team Size - As discussed earlier, the course was based on the USAF Academy design course. In this course, a section of 15 students constituted a team. We tried large teams in the mid-1980s and had mixed results. The major problem with large teams is that individuals can do minimal work and get credit for work done by their teammates. We have determined that the optimal team size for our campus is four to eight students. However, we make exceptions for larger (or smaller) teams when there is sufficient justification.

Peer Evaluations - In order to better understand the relative contributions of individuals to the design, we use a peer review form twice per semester. Students are often very candid in their peer reviews. The relative contributions of the members of a team are easily determined by reading the reviews done by every member of the team. Students are told at the beginning of the semester, at mid-semester, near the end of the semester, and in the syllabus that peer evaluations, along with instructor and TA observations, will be used to determine grade distributions within their design team.

Initially, a single peer review was conducted only at the end of the semester. Later, it became apparent from design team leader comments that having an earlier peer review would be very helpful. Peer reviews are now conducted both at mid-semester and at semester's end. The mid- 
semester peer reviews allow the instructor to counsel students who are not carrying their share of the team's load. The form currently used for Peer Evaluation is provided in Appendix C.

Review Item Description (RID) Forms - In order to simulate industrial practice and to conserve class time during the mid-semester oral presentations, RID forms are used to transmit question to the design teams. Every student in the class who is not on the team making a presentation is given blank RID forms to fill out during the design presentation. All filled-in RID forms are given to the team at the end of their presentation and each RID must be considered by the team in the refinement of their design.

Reviews of Mid-semester Written Reports - The mid-semester written report is, in most cases, the first draft of the final report. The mid-semester reports are submitted electronically, and the TA sees that each student in the class receives one mid-semester report from a team on which he/she is not a member. The goal is for every mid-term report in the class to be seen by at least one person on every team. The rationale behind this is that there is a lot of learning by example in the class, and good organizational and reporting practices demonstrated by one team at midsemester usually become part of every team's final report.

Fewer Lectures - With the introduction of the SE course and the subsystems modeling laboratory course as prerequisites, the need for explaining processes, need for requirements, subsystem characteristics, design steps, and products covered in the prerequisite courses decreased significantly. This provided a significant amount time for of one-on-one and one-onteam communication by the instructor, resulting in earlier recognition of design problems and better solutions to those problems.

Student Responsibility for the Designs - Sometimes, the instructor is the thinker behind the design. In the spacecraft-mission design course under discussion, the design belongs to the students, and the instructor tries to avoid suggesting design alternatives. The whole idea behind the course is to wean the students from needing an instructor to tell them what to do. The design is theirs to make work or to mess up. At the end of the course, the students should be proud of THEIR design - a design that they created - with only a little help along the way.

Course Notebooks - Each student team is required to collect copies of the reference material used in its design and to place it in a notebook and leave it in the design library for use by students in later semesters. This provides later students, working on similar designs, with quick access to the references and work of the earlier teams.

JPL Topics \& Mentors - In 2007, graduates of the department who had gone on to work at JPL began to suggest design topics for student design teams. This has now evolved into a system in which JPL provides design topics and mentors for student teams. Usually, a list of eight to ten topics is provided, giving teams a choice of design problem. The mentors work with the teams throughout the semester and a subset of the JPL mentors come to campus to hear the final oral design presentations at the end of the semester.

The mentors at JPL provide the design teams with expert advice and keep them from going too far down blind alleys in the design process. Communications between mentors and design teams 
take three forms. Email is used extensively and teams often use a university provided conference telephone in a dedicated design conference room to confer with their mentor. Finally, several JPL mentors usually attend our final design reviews. We schedule our final design presentations to match the schedules of the JPL mentors who are able to attend the presentations

Wide Variety of Design Topics - Over the years, a wide variety of space-related design projects have been executed by students in our program. These have included Earth-related projects, Lunar-related projects, Mars-related projects, asteroid and other planet/planet moon projects, topics, and several space-related projects that do not fit into these categories. Appendix D lists more than 170 of these topics.

Evolution of Design Complexity - Over the years, the complexity of the design topics has not increased much, but the level of detailed coverage of the topics has greatly increased greatly. As an example, early student teams would base their lunar mission fuel and propellant requirements on Apollo, Mars missions would involve Hohmann transfers, and outer planet missions would be based on Voyager numbers in a two-body solar system. Today, student teams regularly use Lambert targeting, gravity assists, JPL ephemeris data, and professional level software packages such as Satellite Tool Kit (STK), MAnE, and Copernicus, etc. Furthermore, earlier projects almost never included more than rudimentary communications analyses. Current reports regularly involve communications link budgets, data rate considerations, etc.

Guest Lecturers - Guest lecturers are used to present special topics whenever appropriate. Each semester over the past few years, a retired NASA engineer who worked in the Exploration office at NASA JSC and who did cost analyses for Apollo and the Space Shuttle, has discussed cost modeling with teams. He has provided the teams with access to simple cost modeling tools and has made them aware of the problems of cost modeling. Other guest lecturers are used whenever they become available. Often, representatives of JPL are in Austin on recruiting trips and are glad to talk with the class.

Effects of the Internet - Electronic communications have changed the way that the space design course is taught. The use of course management tools such as Blackboard and email has changed the instructor-student interface. Providing materials for student reference is much easier, and students can and do pose questions at any hour of the day or night. Reports are sent electronically and instructor feedback on those reports is also electronic (edits and comments in Microsoft WORD are employed). The instructor posts sample proposals, presentations, requirement lists, report formats, and reports early in the semester so that the students know the standard to which their work will be compared. This is immensely useful in getting projects started and keeping them on track.

The immense amount of information available electronically has made it much easier for students to research design heritage and to find information about candidate equipment for various subsystems. However, there is still the need for paper documents. A case in point is the AIAA Space Launch Systems document [5]. This document provides the information necessary for launch vehicle choice in one place, avoiding a search over as many as 20 websites for comparable information. 
Grading - Grading is obviously somewhat subjective. Designs are scored on technical merit (need identification, concepts of operations, requirements, constraints, design alternatives, design analyses, alternative selection criteria, final design viability, and design presentation) and team performance. This decides the total number of points available for the team. Individuals within the team are allocated points from within the total number of points based on instructor observations, TA observations, and peer evaluations. It is not at all uncommon for some team members to get high grades (A or A-) while others get grades at the $\mathrm{B}$ or $\mathrm{C}$ level. Once, there were four (A to A-) level grades and one $\mathrm{F}$ grade for a team of five students.

Interim Individual Progress Reports -- In spring 2012, one of the design team project managers requested assistance in determining what his team members were doing and in motivating them to work at a steady pace rather than the "wait and rush" mode of operation characteristic of most students. In response, a request for information was sent to all students in the course requiring the student's name, team name, and three short paragraphs. The paragraphs focused on (1) what the student had accomplished thus far toward the team's design, (2) what the student was currently working on and needed to accomplish in the next three weeks, and (3) what major problems/challenges the student currently faced in getting his/her work done. These reports have been very successful in helping the team leaders to better know what is going on with their team members. Often, students are reluctant to admit lack of progress, slow work, etc., to their teammates, but team leaders indicate that this new report seems to have helped a lot. It is planned to repeat this report at three week intervals throughout the rest of the semester and to incorporate the report as a regular course feature in future semesters.

Course Evaluations -- The student evaluations of this course are high. Student comments about the course have, with one major exception, been very positive. In fall 2007, Lisa Guerra, NASA systems engineer was developing course modules for the Systems Engineering course that would be offered on a pilot basis in spring 2008. We decided to present some of the systems concepts and modules in the design course "to make their jobs easier". This overloaded the students and the course evaluations were significantly lower than either earlier or later. The course ratings, on a 5 point scale, were 0.8 points lower than they had ever been (the course ratings normally fall between 4.4 and 4.6 on the 5 point scale). Student comments that semester made it very clear that the additional material detracted from the quality of the final design. These comments were instrumental in our decision to redesign the curriculum so that the Systems Engineering course would be a prerequisite for the capstone design course.

Impacts of Course Changes -- The evolution of the design course from a single three semester hour course to a seven semester hour sequence has greatly increased the quality of the final design products produced by the student teams. The early (1984-1990) design reports were primitive when compared to current reports. The early reports contained much less detail on system and subsystem masses, few heritage assessments, fewer graphics and CAD elements, no risk assessments, sketchy documentation of system trades, few subsystem details, only basic requirements with no rationales and traceability, and little project costing information. Current reports contain all of these elements in detail and more. Current final report requirements have been written so that reports can be used to demonstrate attainment of various ABET student outcomes. 


\section{What Really Makes a Difference}

Among the course features discussed above, there are several items that stand out in the author's mind as having large impacts. However, what works for the author might not work in a different academic environment.

First and foremost, the detailed syllabus and published course timeline/deliverables list give the students a clear definition of what is expected of them. Giving this information to the students on the first day of class, and reminding them of upcoming events throughout the semester is crucial. Design courses are time intensive this helps to keep students on schedule.

Example documents have large impacts. Students set their goals (level of detail, which items to cover, which formats to use, etc.) based on what earlier students have done. High standards are set by providing examples of good reports and presentations for teams. If students request to see reports that are not considered to be of high quality, identify the weaknesses of the reports/presentations.

The systems engineering prerequisite course and the spacecraft subsystems modeling laboratory course have greatly improved team organization, requirement development and documentation, report completeness, and the level of detail in the subsystems and the associated trade studies. This curriculum change, which occurred with the publication of the 2008-2010 course catalog, is the most important design course change that has occurred in the past decade.

A factor that contributes strongly to overall design quality is the requirement for the midsemester presentation and report. The fact that the teams must organize and present their designs at mid-semester forces the team members to integrate the design and identify conflicts while there is still time for additional design iterates. In preparing the mid-semester report, a team is writing the first draft of the final report. Instructor and mentor feedback on this report, provided more than a month before the final report is due, allows a team to identify and remedy shortcomings of the design before completing the final report.

The wide access to information, both from the internet and from earlier student designs allows/forces the students to consider many design alternatives and to make choices among them. Properly managed, this implies that the students conduct trade studies and develop formal criteria for selection of design elements.

Sharing of Reports/Other Course Information - The author has electronic copies of most of the student reports cited in Appendix D and will share the other instructors when requested. Requests for copies of reports should include the name and semester of the report requested, the name of the instructor requesting the report, the department and institution at which the instructor teaches, and the name/number of the design course (if any) that the instructor teaches. All requests should be sent to wallace.fowler@austin.utexas.edu .

\section{REFERENCES}


1. Johnson, Vicki S; Rumbaugh, Barbara A., Educating for engineering design today - Measuring for excellence tomorrow: The NASA/USRA University Advanced Design Program_32 ${ }^{\text {nd }}$ AIAA Aerospace Sciences Meeting and Exhibit, Reno, NV; 10-13 Jan. 1994.

2. Fowler, Wallace T. and George W. Botbyl, and Steven P. Nichols, Impact of the NASA/USRA Advanced Design Program on the Development of Space Engineering at the University of Texas at Austin, AIAA Aerospace Design Conference, Irvine, CA, Feb 3-6, 1992. Paper AIAA-1992-1044.

3. Guerra, Lisa A., Wallace Fowler, and Martin Brennan, Systems Engineering and Spacecraft Subsystems Modeling as Prerequisites for Capstone Design, Paper AC2011- 1009, ASEE Annual Conference, Vancouver, BC, June 25, 2011.

4. http://spacese.spacegrant.org/

5. Isakowitz, Steven, Joshua Hopkins, Joseph Hopkins, Jr, International Reference Guide to Space Launch Systems, Fourth Edition, AIAA Library of Flight, 2004. 


\section{Appendix A}

\section{Course Syllabus}

The course syllabus shown below is the one used in fall 2011 with several local items required by UT Austin removed (local critical dates, religious holy days accommodation notice, students with disabilities accommodation notice, and student privacy notice).

\section{ASE 374L - Spacecraft/Mission Design \\ Fall 2011}

\section{SYLLABUS}

\section{Unique Number Designation: Instructor}

Time: Location: Teaching Assistant:
13750

Space Flight Technical Area Course Wallace Fowler WRW 415D, 471-4157, fowler2@csr.utexas.edu Office Hours: MWF 8:30-9:30 AM \& MWF 3 - 4 PM MWF 10:00-11:00 AM WRW 113

Web Page: Course documents will be posted on the course Blackboard website.

Catalog Description: Spacecraft systems characteristics, mission requirements, sensors, consumables analyses; mission phases, request for proposal, problem definition, ideation, proposal preparation, conceptual design review, preliminary design development and review, design report preparation. Written reports. Three classroom hours a week for one semester.

Course Objectives: The objective of this course is to provide the student with a team learning experience that brings together content from earlier courses, focusing on the conceptual design of space systems. Students working in teams will learn to develop requirements and synthesize material from earlier courses with material obtained from outside resources to create designs to meet stated engineering needs.

Prerequisites: Aerospace Engineering 366K and $374 \mathrm{~K}$ with a grade of at least $\mathrm{C}$ in each, and credit with a grade of at least $\mathrm{C}$ or registration for Aerospace Engineering $376 \mathrm{~K}$.

\section{Knowledge, Skills, and Abilities Students Should Have Before Entering This Course:}

Communicate technical information accurately and concisely - both orally and in writing, use analysis, computer software, word processors, etc., to define and develop solutions to technical problems in the areas of fluids, solids, dynamics, orbital mechanics, etc., develop solutions to technical problems in the areas of fluids, solids, dynamics, orbital mechanics, etc.

Knowledge, Skills, and Abilities Students Gain from this Course (Learning Outcomes): This course will give students first-hand experience in using the engineering design process. Students will work on real world team design tasks and will perform design team management 
functions. Ethics in engineering and management will be covered and the importance of safety considerations, and reliability. Students will learn to develop a detailed design needs statement from a vague initial design goal. They will learn to carry out engineering trade studies and to work in an arena in which critical pieces of information are often missing. They will learn to make assumptions, to work on the basis of those assumptions, and subsequently to modify or abandon their assumptions as appropriate. They will learn that design is iterative and will develop judgment that will allow them to compare and evaluate design alternatives. They will learn to present their results in a concise, accurate, and professional manner.

Impact on Subsequent Courses: There are no subsequent courses in the curriculum.

Relationship of Course to Program Outcomes: This course contributes to the following EC2000 Criterion 3 outcomes and those specific to the ABET accredited program.

\begin{tabular}{|c|c|c|c|}
\hline Outcome & & Outcome & \\
\hline $\begin{array}{l}\text { a. An ability to apply knowledge of } \\
\text { mathematics, science, and engineering }\end{array}$ & $\sqrt{ }$ & g. An ability to communicate effectively & $\sqrt{ }$ \\
\hline $\begin{array}{l}\text { b. An ability to design and conduct } \\
\text { experiments, as well as to analyze and } \\
\text { interpret data }\end{array}$ & & $\begin{array}{l}\text { h. The broad education necessary to } \\
\text { understand the impact of engineering } \\
\text { solutions in a global/societal context }\end{array}$ & \\
\hline $\begin{array}{l}\text { c. An ability to design a system, component } \\
\text { or process to meet desired needs }\end{array}$ & $\sqrt{1}$ & $\begin{array}{l}\text { i. A recognition of the need for and an } \\
\text { ability to engage in life-long learning }\end{array}$ & \\
\hline $\begin{array}{l}\text { d. An ability to function on multi- } \\
\text { disciplinary teams }\end{array}$ & $\sqrt{1}$ & j. A knowledge of contemporary issues & \\
\hline $\begin{array}{l}\text { e. An ability to identify, formulate, and } \\
\text { solve engineering problems }\end{array}$ & $\sqrt{ }$ & $\begin{array}{l}\text { k. An ability to use the techniques, skills, } \\
\text { and modern engineering tools necessary for } \\
\text { engineering practice }\end{array}$ & $\sqrt{ }$ \\
\hline $\begin{array}{l}\text { f. An understanding of professional and } \\
\text { ethical responsibility }\end{array}$ & & $\begin{array}{l}\text { 1. Begin list of any other outcomes unique to } \\
\text { the program. }\end{array}$ & \\
\hline
\end{tabular}

\section{ABET Program Criteria Achieved:}

\begin{tabular}{|c|c|c|c|c|c|}
\hline Criterion & & Criterion & & Criterion & \\
\hline A. Aerodynamics & & G. Orbital Mechanics & $\sqrt{ }$ & $\begin{array}{l}\text { M. Preliminary/Conceptual } \\
\text { Design }\end{array}$ & $\sqrt{ }$ \\
\hline B. Aerospace Materials & $\sqrt{ }$ & H. Space Environment & $\sqrt{ }$ & N. Other Design Content & $\sqrt{ }$ \\
\hline C. Structures & & $\begin{array}{l}\text { I Attitude Determination } \\
\text { and Control }\end{array}$ & $\sqrt{ }$ & O. Professionalism & $\sqrt{ }$ \\
\hline D. Propulsion & & J. Telecommunications & $\sqrt{ }$ & P. Computer Usage & $\sqrt{ }$ \\
\hline E. Flight Mechanics & & K. Space Structures & $\sqrt{ }$ & & \\
\hline F. Stability and Control & & L. Rocket Propulsion & $\sqrt{ }$ & & \\
\hline
\end{tabular}

Professionalism Topics: The course focuses on team design projects. Teams of four to eight students develop space-related designs. Formal final formal design briefing and report called for in 
the Request for Proposal (RFP) replaces examination requirements. See the RFP for reporting/briefing requirements and grading criteria. Attendance at all scheduled meetings of the design group is required. A mid-term draft report and a final report are required. There will be formal oral presentations prior to turning in each report.

\section{Topics:}

1. Engineering design methodology (Outcome e)

2. Working as a member of a design team (Outcomes $\mathrm{d}, \mathrm{g}, \mathrm{k}$ )

3. Developing a design to meet a need. (Outcomes a, c, e, k)

4. Report writing and presentation of results (Outcome g)

5. Technical, ethical, and societal topics as appropriate to the project (Outcomes a, c, e, k)

Design Assignments: The entire semester involves a team design project. The instructor issues an RFP and the students form a team to answer it. The students develop conceptual designs and present them at a design review. Based on feedback, the students choose from among candidate designs and develop the chosen designs further. Criteria for choosing from among candidate designs are developed and applied. The students develop both oral and written final reports. The final reports are often presented to engineers from NASA and space industry firms in the Houston area.

Laboratory Assignments: The design project is developed in the design "laboratory". The "laboratory" is wherever and whatever is required to accomplish the required design task. This includes library research, web research, writing letters, writing e-mails, making phone calls, looking at the design archives, building models, making posters, etc.

Computer: Computers are used for writing reports (WORD) and presentations (PowerPoint). Spreadsheets are used as appropriate in doing multiple trade studies. Analysis tools such as (NASTRAN, TK Solver, MatLab, etc.), are used as appropriate in doing analyses and trade studies

Text: No single textbook is sufficient for this class - use the library, the web, etc. There is no single textbook that could provide you with the information you will need of this course. Your references are chosen to help guide you through the processes involved in design. Spacecraft design and mission planning information files are available in WRW 409.

\section{References:}

Creative Problem Solving and Engineering Design, Lumsdaine, et. al.,McGraw-Hill, 1999. Space Mission Analysis \& Design, Larson \& Wertz, Third Edition, 2000.

Space Systems Design, French, 1993.

Space Vehicle Design, Griffin \& French, $2^{\text {nd }}$ Edition, AIAA, 2004.

Spacecraft Subsystems, UT Austin, 1993, available on the Texas Space Grant web site: www.txgc.utexas.edu under Higher Education / Advanced Design Program.

Class Format: The class will consist of regular briefings at the beginning of the course followed by class sessions that combine mini briefings, student presentations, and design teams working on their designs. Much class time will be devoted to discussion of specific approaches to design, 
evaluation of candidate designs, mini-lectures on topics of interest to one or more design teams, etc. In this course, your instructor does not know all of the answers. The answers are not in the back of some book. There may not even be a book on some of the topics you will address.

Class Outline / Course Documents : Course documents and a detailed course schedule will be posted on the Blackboard web site for ASE 374L.

Grading: Sixty percent of your individual grade is based on the quality of the design products produced by your team and forty percent of your individual grade depends on your contribution to the design as evaluated by your teammates, the instructor, and the TA. You will be evaluated on the basis on your own work, on your work as a member of a design team, and on the quality of the design, design presentations, design report, design posters, and design models (when appropriate) produced by your team. The course requires a lot of work and a lot of learning. Do not wait - start early and work hard. Teams / individuals who put the work off make the lowest grades. The quickest way to earn a lower grade in this course is to participate poorly as a member of your design team. This has two effects. First, if you participate poorly, your team's overall design effort will be of lower quality and the team's overall grade will be lower. Second, your teammates will be painfully aware of your level of participation and this will be reflected in the peer evaluations at mid-semester and at the end of the semester.

Homework Policy: This is a projects course and the "homework" will be project reports, briefings, analyses, trade studies, etc., as are appropriate for each specific project. Reports and projects are listed below under Deliverables.

Peer Evaluation: You will be required to evaluate each member of your design team (including yourself) twice during the semester. The evaluation form will be similar to that attached to this syllabus. You will be asked to evaluate the overall quality of your team's report, the effectiveness of your team in working together, the quality of your team's design presentations, models, and posters.

Review of the Work of Other Design Teams: You will also be asked to use Review Item Description forms (RIDs) during the mid-term presentations to provide feedback to each team making a presentation. You will also be asked to read the mid-term presentation of one of the other teams and provide comments on it. The other teams will use your comments to improve their designs.

Pacing of Your Design Work: Many design teams make the mistake of thinking that the only times that they really need to work as a team are: (1) to write the proposal, (2) to prepare and deliver the mid-term presentation and written report, and (3) to prepare and deliver the end-of-term presentation and written report. Many teams work all night for several days during the preparation of presentations and reports.

There is a better (and more humane) way to do well in this course. As soon as your team is formed and a design topic is chosen, begin to hold regular team meetings. Organize your team quickly and be ready to modify the organization if things aren't working well. Develop a work breakdown structure for writing the proposal and follow it. Do the same for each of the course milestones. 
Start early and keep on schedule. Communicate efficiently within the team. Everyone should know what every team member is doing and when each task will be completed.

Feedback from Last Semester's Students: As part of the end-of-semester peer evaluations, students in this course last semester provided advice to you about how to succeed in the design course. This "lessons learned" information is posted as the first item under Course Documents on the Blackboard website. Read it today and read it often again until the advice is part of your success strategy.

Deliverables: Each team must deliver the following items at the appropriate times during the semester.

Design Scope Oral Presentation

Design Proposal - 15 to 20 pages detailing background research and your proposed project

Management Proposal-10 to 15 pages detailing team organization, team leadership, team member strengths, and preliminary scheduling

Team e-mail Progress Reports - bi-weekly

Team workload management reports as appropriate throughout the semester

Design Requirements Briefings as specified in the detailed course timeling

Trade study oral/written reports

Mass/Volume/Power oral/written report

Design Oral Mid-semester Presentation - in class or at arranged times

Design Written Mid-semester Report - Submit electronic copy of report \& Presentation Slides

Mid-semester peer review of teammates' contributions to the project

Peer reviews of Mid-term Design Reports (each student reviews one report from another team)

Design Oral Final Presentation - 30 minutes /team in class plus questions

Design Written Final Presentation - Two hard copies plus a CD (report + Presentation )

End-of-semester peer review of teammates' contributions to the project

Design Poster and Model (if appropriate)

Examinations: The design reports and presentations take the place of examinations. The final presentations will be arranged so that personnel from the Jet Propulsion Laboratory in Pasadena, California can attend. This will likely require that all presentations be done on a single day near the end of the semester.

Attendance: Regular class attendance is expected. We meet in class three times per week. I will often talk for the first ten to fifteen minutes of the class period and you will then work in teams. You will meet as teams outside of class as well as in class. These meeting times will be agreed to and arranged by your design teams. You will need to meet a LOT more than this, so choose team members with compatible schedules.

Course Evaluation: The Measurement and Evaluation Center forms for the College of Engineering will be used during the last week of class to evaluate the course and the instructor. The instructor will not have access to these evaluations until after the end of the semester. 


\section{Appendix B}

\section{Course Timeline}

The timeline given below is for a three semester-credit-hour course meeting three times per week in the fall 2011 semester. The later topics on the timeline can be shifted around from semester to semester to fit local scheduling constraints. The primary outside constraint is the timing of the visit of JPL mentors to hear the final design presentations. The students are told at the beginning of the semester that the date of the final presentations will depend on when the JPL mentors can travel to Austin. Items in bold face type denote assigned student presentations and/or submissions.

\section{Capstone Design -- Detailed Schedule: Fall 2011}

Aug 24 Course Introduction / Projects Preview

Aug $26 \quad$ Projects Preview / Teaming Exercise

Aug 29 Trade Trees / Mission Scenarios

Aug $31 \quad$ Trade Trees / Three Key Team Leadership Roles

Sept 2 Teams Formed / Projects Chosen / Team Rosters Submitted

Sept 5 Labor Day - No classes

Sept $7 \quad$ Scoping and ConOps /Proposals Assigned

Sept 9 Requirements / Work on Proposals

Sept 12 Work on Proposals

Sept 14 Preliminary Scope/ConOps Presentations/ Systems Hierarchy / WBS

Sept 16 Design Heritage Discussions with Teams

Sept 19 Preliminary Requirements Presentations/ Work on Proposals

Sept $21 \quad$ Work on Proposals and Requirements

Sept 23 Technical and Management Proposals Due

Sept 26 Project Scope/ConOps Presentations (15 min/team)

Sept 28 Publish Team Website / Work on Requirements

Sept $30 \quad$ Mass and Volume Estimation $\rightarrow$ Implied costs

Oct 3 Requirements Briefings (15 minutes / team)

Oct 5 Report Writing Fundamentals / Work on Design

Oct 7 Trade Study Briefings (15 minutes / team)

Oct 10 Peer Review Instructions/ Intro to RID Forms / Work on Design

Oct 12 Work on Design

Oct 14 Prepare for Midterm Presentations

Oct 17 Midterm Presentations (25 minutes / team) 
Oct 19

Oct 21

Oct 23

Oct 26

Oct 28

Oct 31

Nov 2

Nov 4

Nov 7

Nov 9

Nov 11

Nov 14

Nov 16

Nov 17

Nov 18

Nov 21

Nov 23

Nov 25

Nov 28

Nov 30

Dec 2
Midterm Presentations (25 minutes / team)

Prepare Written Midterm Report / Work on Design

Prepare Written Midterm Report / Work on Design

Written Midterm Reports Due / Work on Design

Risks / Work of Design

Mass / Volume / Power Budgets (10 min/team)

Costs Briefing - Dr. Humboldt Mandell

Teammate Peer Reviews Due - Prep Final Briefing / Report

Requirements Updates (10 minutes / team)

Peer Reviews of Midterm Reports Due / Work on Design

Safety, Ethics, Liability Discussion / Work on Design

Prep for Final Briefing / Final Report / Work on Design

Prep for Final Briefing / Final Report / Work on Design

Final Briefing Day (50 minutes / team) ** JPL Mentors Here ${ }^{* *}$

Work on Final Design \& Final Report

Work on Final Design \& Final Report

Work on Design and Final Report

Thanksgiving Break - No class

Work on Final Report

Final Reports Due / Return Documents / Course Evaluation

Teammate Peer Reviews Due/ Celebrate - the class is over 


\section{Appendix C}

\section{Peer Evaluation Instructions}

1. Your team has n members counting yourself. Build a matrix with the names of all of the members of your design team in the left column, starting in the second row. Starting in the second column of the first row, place the number $4 n$, in the next column insert $4 n-1$, in the next column insert $4 n-2$, etc., out to the column with value $2 n$.

2. The values in the column headings are possible values for the number of grade-points which might be awarded for your team's effort. Based on your observations of your team, fill the matrix with the number of grade-points which each team member would deserve if the team grade rating (with a maximum score of $4 \mathrm{n}$ ) was the number at the top of the column. Each entry must be $0,1,2,3$, or 4 . Be careful to make your evaluations consistent - there should be no increases in any row as we go from left to right.

The matrix, for a three-member team, might look like the following.

\begin{tabular}{|l|l|l|l|l|l|l|l|l|}
\hline & 12 & 11 & 10 & 9 & 8 & 7 & 6 & \\
\hline \hline Joe Jetpack & 4 & 4 & 4 & 3 & 3 & 2 & 2 & \\
Melissa Best & 4 & 4 & 4 & 4 & 4 & 4 & 3 & \\
Willie Makit & 4 & 3 & 2 & 2 & 1 & 1 & 1 & \\
\hline
\end{tabular}

3. For each member of your team (including yourself), write a five to seven sentence paragraph describing that team member's overall contributions to the design project.

4. Finally, rate your team on the following items using a scale of 0-100.

Teamwork (after the mid-term report)

Quality of final oral presentation

Quality of final written report

5. Are there cautions or suggestions that you would give to future teams? If so, write them here. Use the back of this page or an additional page if necessary. 


\section{Appendix D}

\section{UT Austin Student Design Topics}

The list of student design topics given below is organized by mission type. The design topics marked with (SE) are those for which the Systems Engineering course was taken as a prerequisite course. All projects except those marked with an asterisk were done as part of the aerospace engineering curriculum. Those marked with the asterisk $(*)$ were done as part of a mechanical engineering curriculum with the author as the principal project advisor. The designation (Sxx), (Fxx), or (Suxx) indicates when the design project was done (S indicates spring, F indicates fall, Su indicates summer $\mathrm{xx}$ indicates the year the project was done).

\section{Earth Orbital Missions}

Advanced Fully-Reusable Space Transportation System (S84)

Manned Maneuvering Unit Rescue Ejector*(S87)

Feasibility Study of Methods for Stopping the Depletion of Ozone over Antarctica (S88)

Gateway - An Earth Orbiting Transportation Node (S88)

Earth Orbiting Satellite Service and Repair Facility (F89)

Solar Power System (S90)

Comprehensive Orbital Debris Management Program (F90)

Microgravity International Research (S90)

Space Station Based Micro-acceleration Experiment Platform (S90)

Space Debris Removal System (F90)

Texstar -- The All-Texas Educational Satellite System (S90)

Personnel Launch System / Family of Heavy Lift Launch Vehicles (S91)

Satellite Power System (S91)

SHARC - Space Habitat, Assembly and Repair Center (S92)

AERCAM - Space Station Monitoring System (F92)

Small Satellite Design for DSN Testing and Training (S93)

Converting the Minuteman Missile into a Small Satellite Launch System (F93)

Comet/Asteroid Planetary Defense System (S94)

Minuteman II Launched Small Satellite (S94)

Space Traffic Control System (S95)

Mobility System for Propulsively-Inert Space Station Elements (S95)

Space Station Lifeboat (F95)

Nadir Window Sensor for the ISS (S98)

VALOR - Satellite to Qualify Electronics for High Radiation Environments (F99)

BEVOS - Balloon orbital Element de-Orbiting Satellite (F99)

Project GRAVMAP - Mapping Earth's Gravity Field (S96)

CANDEL - CANsat DELivery Project (S00)

Space Based Solar Power (F00)

APTUS (Application for Tether United Satellites) (F00)

AEGIS (Autonomously Executing Guided Interceptor System) -- ISS Debris Protection (F00) 
Drag-Sat - Atmospheric Explorer (F01)

Electric Propulsion Facility on the ISS (F01)

Ergonomic Flight Simulator Interface for Use as Exercise Equipment in Low-Gravity (F03)

LowGME - Astronaut Exercise Device (F04)

InstaSat - Rapid Response NanoSatellite (F04)

Advanced Recreational Motivational System to Reverse the Onset of Negative Micro-Gravity Effects (F05)

PARADIGM -- Platform for Autonomous Rendezvous and Docking with Innovative GN\&C Methods (F05)

The O.M.E.G.A. Project (Observing and Monitoring Earth's Gravity and Atmosphere) - A GRACE Mission Follow-on (F05)

Design of a Fitness Module for the International Space Station (S01)ubeSat Design (S03)

Development of Motivational Exercise Equipment for Use in Microgravity (S05)

EVA Compatible Fluid Quick Disconnect* (S05)

UTSGS (U of Texas Satellite Ground Station) (F06)

Plug \& Play Satellite (F08)

EOS - Satellite LEO Assembly System (F08)

SECC - CubeSat Constellation and Modularization Study (F11)

ROOD (Removal Of Orbital Debris) (F11)

\section{Lunar Missions}

Lunar Habitat (F85)

Moonport / Transportation Node in Lunar Orbit (S87)

Bootstrap Lunar Base (F87)

Lunar Lander Transformable into a Portal for an Underground Lunar Base* (F87)

Lunar Construction Shack Vehicle (S88)

SERV (Space Emergency crew Rescue Vehicle) - Moon-to-Earth Ambulance (F88)

Lunar Farside Observatory (F89)

Lunar Polar Coring Lander (S90)

IIs of Texas Mission - Lunar Oxygen Production (S95)

ColdConnect Project - Lunar Farside to Earth Communication System (S96)

Thermal and Micrometeorite Protection System for an Unmanned Lunar Lander* (F89)

Radiation Protection Alternatives for a Lunar Base Research Outpost* (S88)

Health Care Needs for a Lunar Colony \& Design of a Permanent Health Care Facility* (S89)

Unmanned Lunar Cargo Lander that Reconfigures into a Shelter for a Habitation Module or

Disassembles into Parts Useful to a Permanent Manned Lunar Base*(F89)

Self-Unloading, Reusable Lunar Lander (F90) (S91)

Heavy Lift Lunar Launch System (F90)

Extended Duration Lunar Lander (S93)

LILBITS (Lunar Independent Laser-Based Intermediary Transmission Systems) - Lunar Farside Communications (S96)

Lunar Sample Return Mission (F97)

BALSAR (Ballistic Arbitrary Location Lunar Sampler and Retriever) (F99)

Selini Lunar Farside Communications (F99)

LUCY - Lunar Cycler (S00) 
Lunar Return Missions (S00)

Solar Power System for a Lunar Habitat (F05)

Lunar Sample Harvester (F05)

Lunatics - Implementing a Lunar Power Source by Landing a Nuclear Reactor (F05)

RSVP Lunar Habitat - Self Landing Mobile Lunar Habitat (F05)

LHEV - Lunar Habitat and Exploration Vehicle (F06)

LunEx - Express Delivery to the Moon (Su06)

BEES (Beyond Earth Establishment Surveys) - Lunar Polar Surface Explorer (S10)

TEVO (Telescopic Earth Viewing Observatory) (S10)

LunarLock - Minimum Air Loss Lunar Airlock (F06)

SMART Express (Seismic Moon Anomaly Remote Transmitter) (F06)

FARSIDES (Functional Application and Reuse of Secondary Interchangeable DEscent Stages) (F06)

ACME (American Cargo Moving Endeavor) - Lunar base supply system (F07)

HERMES - Lunar Pressurized Rover (F07)

OPTIMUS - Lunar Cargo Lander (F07)

Lunar GEM (Geological Exploration Mission) (F07)

HERMES - Lunar Surface to Surface Communication System (F08)

LEX (Lunar EXpeditionary Rover) (S11)

LOLIPOP (Lunar Orbiter and Landers Investigation with Penetrators Observing Pressure Waves) (S11)

\section{Mars Missions}

Manned Mars Mission Project - GOTC (F85)

Manned Mission to Mars (F85) (F86)

Fast Crew Transfer Vehicle to Mars (S88)

Phobos Industrial Production and Supply Base (F86)

Mars Logistics Lander Convertible to a Rocket Hopper (F88)

Manned Base Design and Construction Issues for a Mars/Phobos Mission

Mars Investment for a New Generation (Robotically Constructed Mars Base) (S89)

Mars/Phobos Transportation System (S89)

Robotically Constructed Production and Supply Base on Phobos (S89)

Systems Integration for Mars Planetary Operations Networks (S92)

Integrated Mars Transportation System (S92)

PERCIVAL Mission to Mars (F92)

Satellite Observation System for Space Station Freedom (F92)

Project Aeneas - Robotic Exploration Mission to Mars \& Phobos (F93)

SPUD - Searching Phobos for Unverified Dampness (F95)

MARVIN - Unmanned Mission to Mars with Sample Collection and ISRU (S94)

Flag and Footprints Mission to Mars (F97)

Revised / Redesigned Flag and Footprints Mission to Mars (S98)

Fast Transit Mission to Mars (F98)

Mars Personal Transport (F98)

Heavy Mars Lander (S98)

Mars Surface Transportation System (S99) 
Automated Construction of a Mars Base (S00)

Mars Rover (F01)

Mars Mission Anytime Abort (F01)

VASMIR Engine Test Mission to Mars (F01)

VASMIR Test Mission (F02)

Manned Mars Surface Vehicle (F03)

SatNet Mars Navigation System (F03)

Transformable Mars Lander (F03)

Mars Arcology (Mars Base) (F04)

Mars Exploration Habitat (F04)

ESCAPE (Expose, Sublimate, Condense, Analyze, Process, Evaluate) - Mars Mining (F04)

Aries: An Unpressurized Mars Rover (F04)

Mars Aerial Exploration (F04)

Aeolus - Mars Tumbleweed Sensor Deployment System (F05)

Project Tumble-Drop - Another Tumbleweed Sensor Deployment System (F05)

Re-architecture of the Design Reference Mission to Mars (S01)

Artificial Gravity Transport for a Manned Mars Mission (S02)

HOME (Habitat for an Operational Mars Expedition) (F07)

Mars UAV (S10)

MSSRE (Mars Surface Sample Return Expedition) (S10)

\section{Asteroid / Other Planetary Missions}

Asteroid Prospector (F87)

Europa Explorer Mission (F87)

Asteroid Exploration and Utilization (F91)

Energy Requirements for Asteroid Access (S97)

Venus Sample Return Mission (F00)

Earth Crossing Asteroid Deflection Study (F02)

Asteroid Rendezvous and Sub-Surface Composition Study (F02)

Reconnaissance Mission to the Edge of the Solar System (F02)

Jovian Atmosphere Compositions Explorer (F02)

LIFE - Life Inside Frozen Europa (F02)

Mars In-Situ Resource Utilization Network (F02)

OPP (Operation Planet Probe) - Search for Life on Europa (F03)

Asteroid Deflector 1 (F03)

Asteroid Deflection by Stand-Off Nuclear Detonation (F03)

Mission to Titan (F03)

Stepping Stone - Asteroid Chemistry Mission (F03)

Comet Asteroid Planetary Defense System (F04)

IPS - Interplanetary Positioning System (F04)

APEX - Autonomous Sample Return from a Near Earth Asteroid (F04)

PLATEPUS - Pluto Lander And Terrain Plotting Utilization Survey (F05)

JUPITER - Jovian Unit Processing Intelligent Terrain and Environment Reconnaissance (F05)

KOOLSat - Kuiper belt Orbiting Observation Laboratory Satellite (S03) 
ARES - Asteroid Rendezvous and Exploration Spacecraft (F06)

NERD (Nuclear Energy Rubble-pile asteroid Deflection) (F06)

RAM (Reconnaissance of Apophis Mission) (F06)

Cerberus - Tracking Apophis (F07)

DORA the Europa Explorer (S09)

ROTR - Return of the Ring - Saturn Ring Sample Return (S09)

TITAN EX - Titan Exploration Mission (S09)

EVE - Enceladus Mission (S09)

DSM (Deep Space Miners) - Comet Sampling Mission (F09)

HADES - Pluto Orbiter (F09)

Hanuman - Asteroid Deflection Study (F08)

NEWTON - Neptune Orbiter / Triton Lander (F08)

ARMOR - Apophis Sample Return (S10)

EIEIo (External and Internal Exploration of Io) (S10)

MIoMI (Mission to Io: Maneuver and Investigate) (F10)

SEA (Subsurface Europa Analysis) (F10)

Venus Explorer - Orbiter/Balloons/Lander (F10)

CHASM (Carbonaceous Hydrous Asteroid Surface Mission) (S10)

TAUNTAUN - Titan Orbiter Mission (S10)

TRIDENT (The Really Interesting Discoverer and Explorer of Neptune and Triton) (S10)

SMART - Main Belt Asteroid Sample Return (F11)

ETNA - Enceladus Ice Plume Sample Return (F11)

\section{Miscellaneous Projects}

Minimum Loss Airlock for Low Gravity Environments (F86)

Manned Maneuvering Unit Rescue Ejector*(S87)

MODSTAR - A Fundamental Study of Modular Spacecraft (F03)

Self-Automated Repair Robot System (F03) 